\title{
EARLY WEIGHT BEARING AFTER INTERNAL FIXATION OF TRANSCERVICAL FRACTURE OF THE FEMUR
}

\author{
Preliminary Report of a Clinical Trial
}

\author{
George Abrami and Jack Stevens, Glasgow, Scotland \\ From the University Department of Orthopaedics, Western Infirmary, Glasgow
}

For many reasons, affecting both the patient and the hospital service, it would be desirable to recommend early weight bearing after operation for patients with transcervical fracture of the femur treated by internal fixation if it could be established that this would have no harmful effect on the degree of fixation or on the ultimate fate of the fracture.

There is a wide divergence of opinion about the length of time that these patients should avoid walking on the affected limb. King (1939) believed that weight bearing before the fracture was firmly united was one of the worst mistakes that could be made; Banks (1962) thought that three to five months after operation might be too soon for the limb to bear weight because this should only be permitted when there was radiographic evidence of union. The same conclusion was reached by Fielding, Wilson and Zickel (1962) after a study of 514 patients. A few surgeons, on the other hand, have encouraged their patients to walk much earlier than the customary three months after operation. Murley (1959) instituted partial weight bearing ten to nineteen days after operation in forty-one patients who progressed to unguarded weight bearing at three to six months, and found that 70 per cent of the fractures united. His point that early weight bearing after accurate reduction and sound fixation was not disadvantageous was reaffirmed by Garden (1961), whose seventy-seven patients started full weight bearing at an average interval of five days after operation. The rate of union was 75 per cent in this series. Spotoft (1949) showed experimentally that fractured femoral necks which were accurately reduced and well nailed could withstand repeated heavy strains; he allowed his patients to walk early, claiming a 94 per cent rate of union.

There has been no previous report of a clinical trial to compare the effects of early and late weight bearing in patients with transcervical femoral fractures treated by internal fixation, and a preliminary report on such a trial is now presented. It is believed that two questions should be answered: whether early walking increases the rate of failure of fixation of the fracture in the first six months after operation; and whether this programme of management has any effect on the ultimate fate of the fracture or the patient. This report seeks to provide an answer to the first of these questions.

\section{MANAGEMENT OF THE TRIAL}

The patients included in the trial were all those who had sustained a fresh, displaced transcervical fracture of the femur and who were fit enough to undergo reduction and internal fixation with a sliding nail-plate, designed by Mr J. T. Brown of this department. After operation, but according to the sequence of their admission to hospital, patients in comparable five-year age groups were randomly allocated to either the early or the late weight-bearing groups. A further assessment was made two weeks after operation when antero-posterior and lateral radiographs of the fracture were compared with those taken at operation. Furthermore, any patient from either group who was regarded as being unfit from another cause (such as deep venous thrombosis, cardiac or pulmonary complication, or senility) for the early weight-bearing régime was discarded from the series at this stage. Patients in the early weight-bearing group then started walking with unguarded weight bearing on the affected leg two weeks after operation, whereas this was not permitted for a further ten weeks in those patients in the late weight-bearing group. 
Subsequent assessment was made by clinical and radiographic examination three months and six months after operation. At these times the state of affairs was defined as either a "failure" where there was mechanical failure of fixation and redisplacement at the fracture site, or " satisfactory" when the fixation device continued to hold the fracture fragments even though union was unlikely to be present and some absorption and impaction at the fracture site may have occurred.

\section{RESULTS}

A total of 124 patients have so far been included in the trial and followed for three months. Fifty-one in the early weight-bearing group and fifty-six in the late weight-bearing group have been followed for six months, the difference in numbers resulting from random as opposed to alternate selection.

The results are summarised in Table I. Three months after operation there were five failures and fifty-seven satisfactory results in the early weight-bearing group, the corresponding numbers being eight and fifty-four in the late weight-bearing group. At six months there were ten failures in the early weight-bearing group and nine in the late weight-bearing group.

TABLE I

Results of Early Weight Bearing and of late Weight Bearing in Patients with Fracture of the Femoral Neck

\begin{tabular}{|lcccc|}
\hline \multirow{2}{*}{ Result } & \multicolumn{2}{c|}{ At 3 months } & \multicolumn{2}{c|}{ At 6 months } \\
\cline { 2 - 4 } & Early & Late & Early & Late \\
\hline Satisfactory & 57 & 54 & 41 & 47 \\
\hline Failure & 5 & 8 & 10 & 9 \\
\hline
\end{tabular}

\section{SUMMARY AND CONCLUSIONS}

1. A preliminary report is presented of a clinical trial to compare the results of early and late weight bearing in randomly selected patients of comparable age groups whose displaced femoral neck fractures were treated by internal fixation with a sliding nail-plate.

2. When 124 patients were assessed at three months and 107 at six months after operation there was no significant difference between those who started unguarded weight bearing two weeks after operation and those who avoided weight bearing for three months.

3. Early weight bearing appears to have no harmful effect on the early post-operative stability of this fracture when a sliding nail-plate is used for fixation.

4. Further information is necessary before any conclusion can be reached about the effect of early weight bearing on the ultimate fate of the fracture and of the femoral head. For this reason, and also to increase the numbers of patients in the series, the trial is continuing and the patients are being followed up for a three-year period.

We wish to express our thanks to all the surgeons in the Orthopaedic Department, Western Infirmary, Glasgow, for their cooperation in the conduct of this trial and for allowing us to report on their patients.

\section{REFERENCES}

BanKs, H. H. (1962): Factors Influencing the Result in Fractures of the Femoral Neck. Journal of Bone and Joint Surgery, 44-A, 931.

Fielding, J. W., Wilson, H. J., Jun., and Zickel, R. E. (1962): A Continuing End-Result Study of Intracapsular Fracture of the Neck of the Femur. Journal of Bone and Joint Surgery, 44-A, 965.

GARDEN, R. S. (1961): Low-angle Fixation in Fractures of the Femoral Neck. Journal of Bone and Joint Surgery, 43-B, 647.

KING, T. (1939): The Closed Operation for Intracapsular Fracture of the Neck of the Femur. British Journal of Surgery, 26, 721.

MurLeY, A. H. G. (1959): Early Weightbearing in the Treatment of Fractured Neck of Femur. Lancet, i, 24. Spotoft, J. (1949): Osteosynthesis of the Neck of the Femur. Journal of Bone and Joint Surgery, 31-A, 836. 